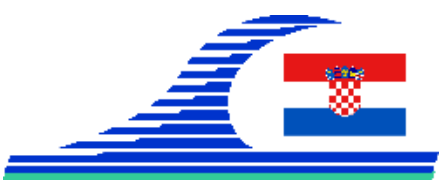

Conférence Méditerranéenne Côtière et Maritime EDITION 4, SPLIT, CROATIA (2017)

Coastal and Maritime Mediterranean Conference

Disponible en ligne - http://www.paralia.fr - Available online

\title{
Seascape modeling and marine territories monitoring using multi-sensor data fusion: a new approach to leverage existing anthropic pressure
}

\author{
Jean-Marc TEMMOS ${ }^{1}$, Claire NOEL ${ }^{1}$, Simon MARCHETTI $^{1}$, Eric BAUER $^{1}$
}

1. SEMANTIC TS, 1142 Chemin de St-Roch, 83110 Sanary-Sur-Mer, France.

temmos@semantic-ts.fr

\begin{abstract}
:
This paper presents recent improvements performed by SEMANTIC TS in monitoring seascapes using a completely enhanced surveying framework and a newly developed algorithmic and methodological toolkit. First, the mini oceanographic platforms developed and their various embedded sensors are described. Then the method for characterizing vegetation and sediment on the seabed using the acoustic response from a conventional single beam echo sounder is exposed, along with the benefits of the data fusion approach and the associated developed methodology.

Eventually, the crowdfunding platform launched by SEMANTIC TS to host environmental coastal projects is presented as a new way to fund comprehensive and accurate long term underwater biodiversity hot-spots monitoring using the previously described methodology.
\end{abstract}

Keywords:

AGDS, Seabed, Classification, Crowdfunding, Segmentation, Underwater landscape modeling, Data fusion, Methodology, Seascape, Underwater landscape 
Mediterranean rocky coasts:

Features, processes, evolution and problems

\section{Introduction}

SEMANTIC TS is a research and development company (founded in 1993) in oceanographic acoustics, leading research since 2004 in the fields of mapping and monitoring of subsea areas. Proposing underwater diving Guides from 3D data in the early 2000s, the whole chain ranging from data acquisition to rendering has been highly improved in the last years. Both the technology and methodology developed now enable us to propose high resolution, optimized and accurate means of seascape monitoring from dedicated support ships. This approach has been validated on various underwater spots and we now propose a new platform to leverage anthropic pressure on some diving spots thanks to crowdfunding.

\section{Instrumented platforms}

The following equipment's are operated simultaneously from a small oceanographic ship dedicated to research and mapping of the coastal waters:

- An interferometric side scan sonar (GEOSWATH+) that makes possible the acquisition and realization of very well georeferenced side scan sonar mosaics as the same time as the acquisition of high density multibeam bathymetric data in very shallow water environment ( 0.5 to 20 meters).

- Towed side scan sonar is used for deeper environment (KLEIN 3900).

- Internet and VPN high rate (data transmission / reception).

- Mini-SVS Valeport profiler (Sound velocity profiles acquisition).

- Motion sensor Coda Octopus FS185+ for positioning and motion correction.

- 2 D-GPS RTK Novatel for location and motion correction.

- Ground truth georeferenced video system, (1).

- Multi-Beam high resolution echo sounder R2Sonic 2020.

- Single Beam eBeem echo sounder capable of seabed classification (AGDS), (1). Some of these sensors (1) have been developed by SEMANTIC TS. These sensors have been integrated into specifically designed support ships to allow simultaneous data acquisition, thanks to specifically developed supervisor software.

The support boats are fully dedicated to monitoring shallow water areas. They are light, small, have a very shallow draft and are extremely manoeuvrable. Ship embeds platform positioning systems, acoustic sensors and ground truth systems. It is able to produce energy to simultaneously process all the instrumentation. High speed 4G internet connection aboard allows real time D-GPS RTK corrections, from land reference DGPS station, see figures 1,2 and 3. 
Mediterranean rocky coasts: Features, processes, evolution and problems

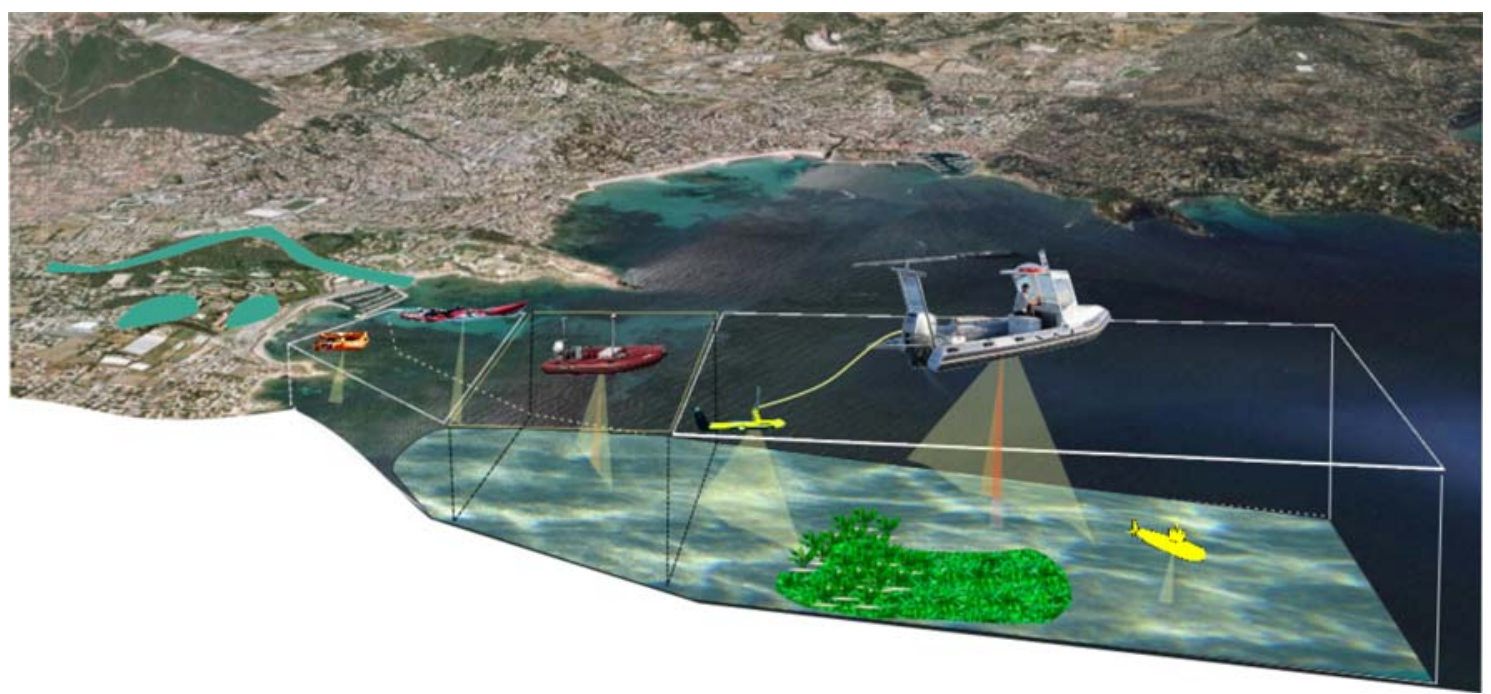

Figure 1. Broad range of oceanographic support boats developed by SEMANTIC TS: Since very shallow waters (laguna and river) up to deep waters (AUV) via coastal waters (mini server units).

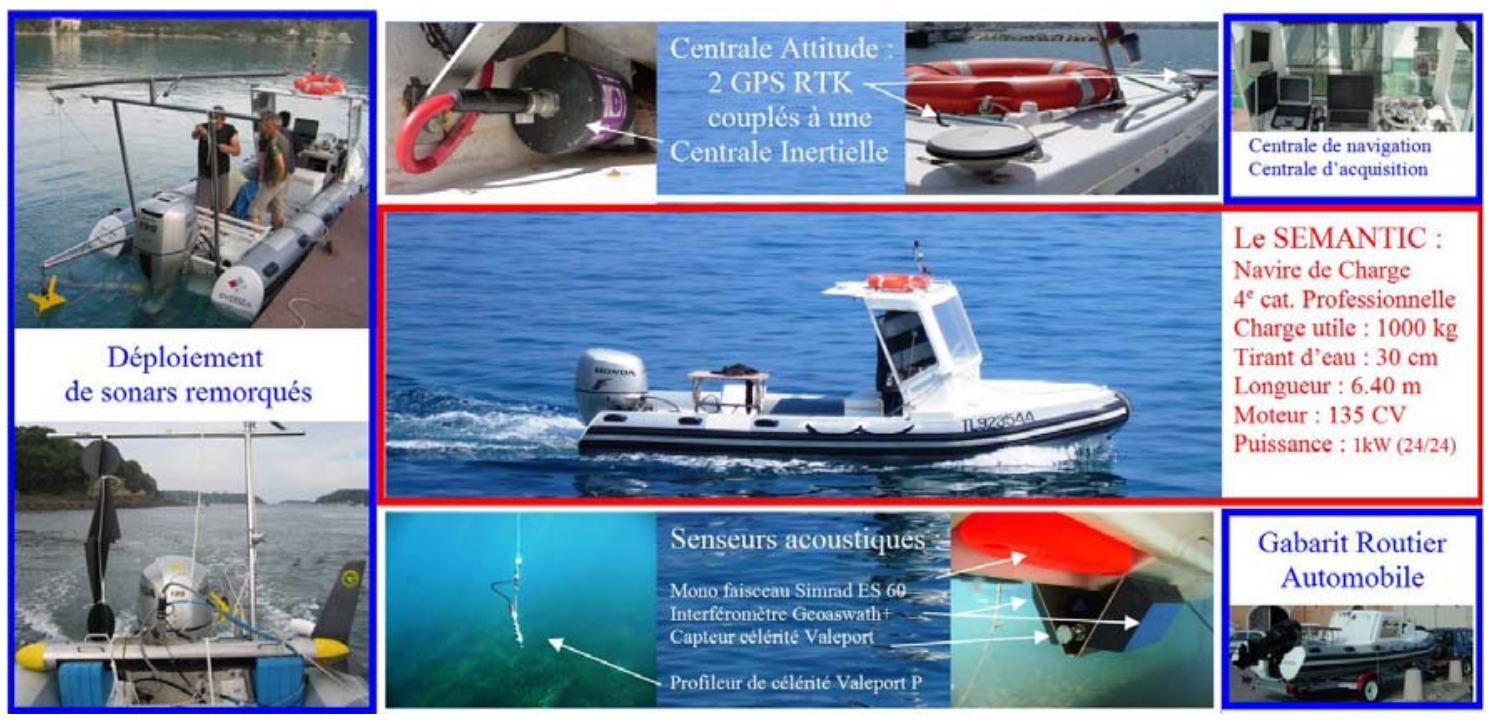

Figure 2. Fully instrumented oceanographic ship (comments are in French).

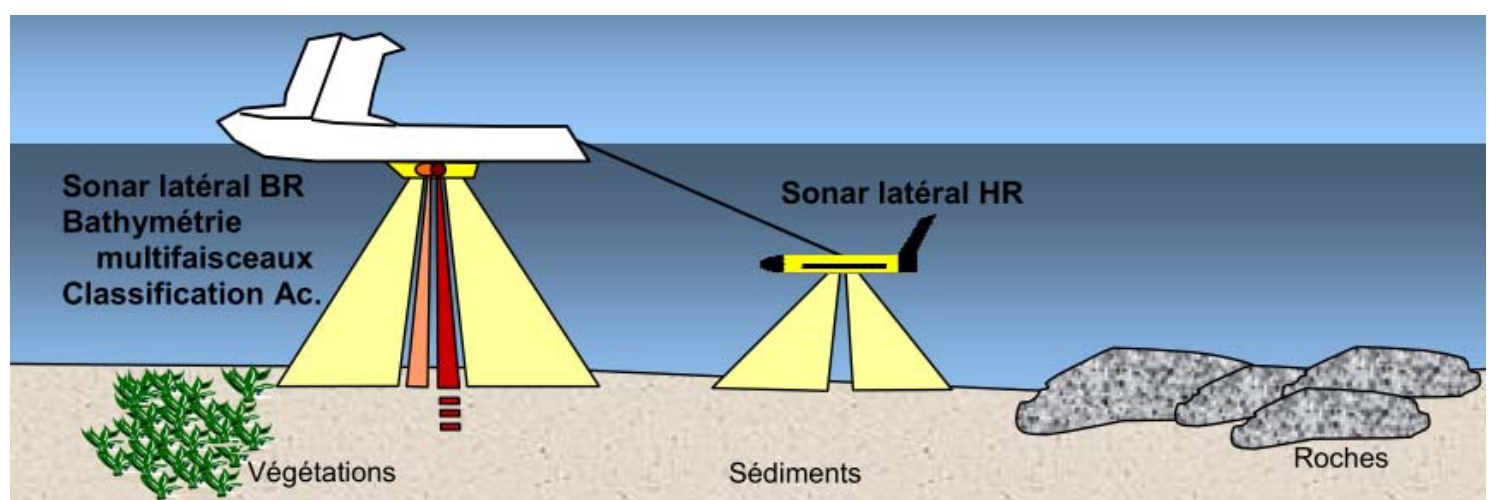

Figure 3. Multi-sensor approach (comments are in French). 
Mediterranean rocky coasts:

Features, processes, evolution and problems

\section{Data fusion and methodology}

Power of data fusion concept relies on the quality of the data and on their complementarities. Data fusion methods and software allow us to merge the different layers of information collected by the ship to take the most of the underwater environment thanks to only one survey:

- 3D bathymetric data.

- Micro-roughness derived from precise bathymetry.

- Side scan sonar imagery in grey levels, producing information about reflectivity, and seabed nature.

- Acoustic Ground Discrimination System. This method uses the back scattered signal from a dual frequency echo sounder (SIMRAD ES60 - $38 \mathrm{kHz}$ and 200 $\mathrm{kHz}$, and the new SEMANTIC eBeem $400 \mathrm{kHz}$ echo sounder). It provides information about presence and absence of vegetation, halieutic resources and bottom roughness and hardness.

- Video and photo imagery.

- Ground truth sampling.

\subsection{AGDS methods}

These specific methods developed by SEMANTIC TS are devoted to vegetation and sediment classification. The shape of acoustic bottom impulse response from a scientific echo sounder is recorded simultaneously with centimetric GPS position. As sand and vegetation have different acoustic signature shapes, we have developed a signal processing algorithm based on discriminant analysis and energy level of the bottom reflected impulse response. The method initially developed to Posidonia characterization is also efficient for zostera or laminaria localization and cartography. Simultaneous measurement using this method then increases the performance of multi sensors fusion method, see figure 4 .

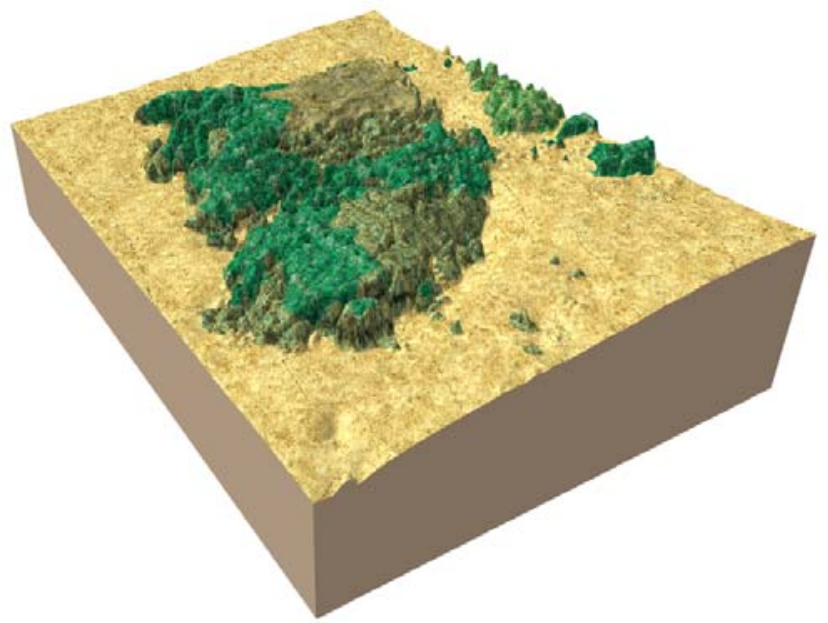

Figure 4. Example result implementing seabed nature information. 
Mediterranean rocky coasts:

Features, processes, evolution and problems

To improve the data fusion process and to be able to propose rendered data in a more user friendly way, we have developed several methods, algorithms and processes:

- Semi-automatized filtering, segmentation and contouring software and methodology.

- Post processing of data acquired to build 3D georeferenced models online.

- Calibration and validation methodology, including sampling analysis, ground truth from video and diving inspection.

Developed methodology and toolkit ensure merging data in a consistent way and keeping information about precision and resolution of the final map, see figure 5.

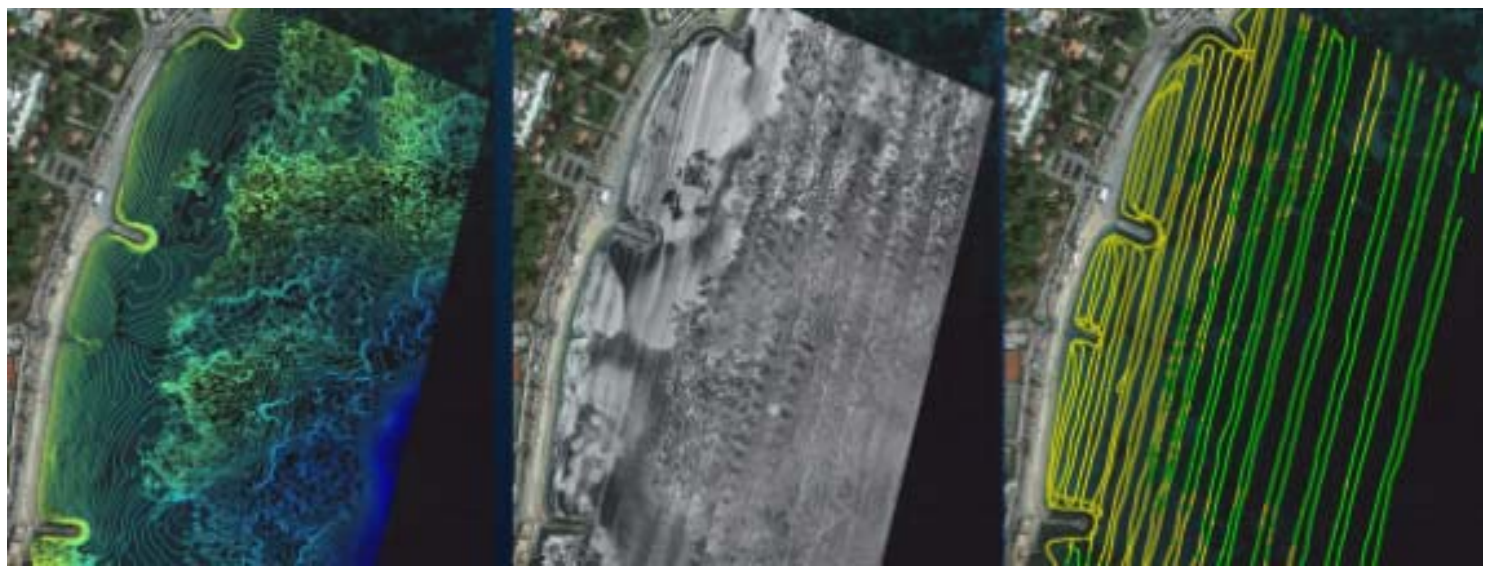

Figure 5. Various layers of information,

from left to right: bathymetry, side scan sonar imagery and AGDS classification.

\section{Crowdfunding platform}

This multi-sensor data fusion and AGDS system approach has been validated on various underwater spots. Thanks to its maturity level, we are now in position to push this approach to the next level.

There is indeed a significant demand for underwater spots mapping and monitoring, both from diving clubs, tourism related companies or administratives, and even from concerned citizens. These spots are subject to massive anthropic pressure (noise, pollution, marine life interaction...). Unfortunately, there is a critical lack of funding to support mapping projects on a large scale. This has recently leaded us to create a new crowdfunding platform to host projects fulfilling the following criteria:

- Having an environmental objective.

- Contributing to awareness of environmental issues.

- Targeting a marine territory area.

- Raising interest for a pool of several users. 
Mediterranean rocky coasts:

Features, processes, evolution and problems

Main objective of the platform is:

- To pool costs and means.

- To monitor today unfocused areas because lack of funding.

- To propose rewards to contributors from the 3d data acquired.

- To collect public environmental data.

- To help the SNSM by donating the association part of the collected money.

At first stage, expected stakeholders are:

- Divers / Snorkelers.

- Boaters (Shipping, Yachting).

- Administration.

- Academics / Universities.

- Ports and Harbors.

- Indutrials.

- Citizens.

A dedicated cloud platform has also been implemented for the online rendering of the collected results, thus allowing the whole data processing chain from acquisition to cloud hosting of the resulting 3D models, see figure 6 .

\section{Conclusion}

Multi sensors survey, using AGDS and ground truth method operated simultaneously and coupled with new methodology for data fusion have proven successful in monitoring underwater spots. Both high precision and resolution now achieved allow us for accurate monitoring of seascapes. Unfortunately some very popular touristic diving spots or critical areas, subject to important anthropic pressure and worth being monitored are yet unsupervised due to lack of public funding.

Crowdfunding approach is therefore proposed to help gathering small-scale investors, divers, boaters, concerned citizens with a common environmental goal. The first projects will be host on the platform starting 2018 . 
Mediterranean rocky coasts:

Features, processes, evolution and problems

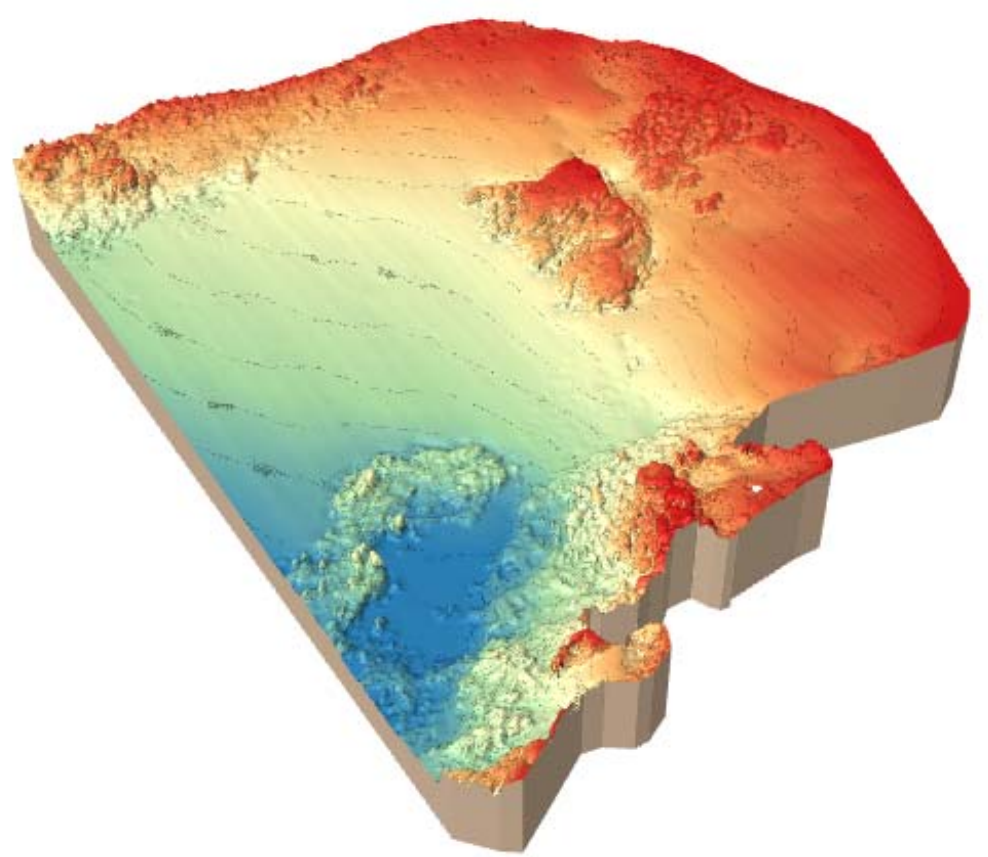

Figure 6. Example result implementing seabed nature information.

\section{Acknowledgements (in French)}

This work relating to the applications of multi-sensor fusion monitoring methodologies in the framework of monitoring networks is supported by the RMC Water Agency and the development of the SACLAF mini system carried out with the support of the Future Investments of the State entrusted to ADEME, and the support of BPI France.

\section{Bibliography}

CHIVERS R. C., EMERSON N., BURNS D. R. (1990). New acoustic processing for underway surveying. The Hydrographic Journal, n56, pp 8-17.

NOEL C., COQUET M., ZERR B., LELONG P., BONNEFONT J.-L. (2007). Pertinence de la méthode DIVA pour l'interprétation des mosaïques sonar latéral. Third Mediterranean Symposium on Marine Vegetation, March $27^{\text {th }}-29^{\text {th }}, 2007$, Marseilles, pp 209-214.

NOEL C., COQUET M., ZERR B., PERROT T. (2008). Acoustic data fusion devoted to underwater vegetation mapping. ECUA - SFA, Paris, 28 juin- 4juillet 2008.

NOEL C., COQUET M., MARCHETTI S., EMERY E., KANTIN R., TRUT G., DALLOYAU S., PLUS M. (2009). Cartographie de l'herbier à zostera marina du bassin d'Arcachon par fusion multi-capteurs. Colloque CARtographie des HAbitats Marins Benthiques : de l'Acquisition à la Restitution - CARHAMB'AR, Brest, 3-5 février 2009.URL http://www.carhambar.org/content/download/41657/325809/file/NOEL.pdf 
Mediterranean rocky coasts:

Features, processes, evolution and problems

NOEL C., COQUET M., MARCHETTI S., BAUER E., EMERY E., SAUZADE D., KANTIN R., COUDRAY S., TRUT G. (2009). Comparison of coastal marine vegetation mapping method. Revue Paralia, Volume 2 (2009) pp 5.13-5.24,

DOI: 10.5150/revue-paralia.2009.005

NOEL C., TEMMOS J.-M., MARCHETTI S., BAUER E., COQUET M., TRUT G., RIGOUIN L., AUBY I., BLOUET S., DUPUY DE LA GRANDRIVE R., CHERE E. (2017). Nouveaux outils de cartographie et de monitoring par fusion multi- capteurs : Application aux zostères d'Arcachon et au coralligène de l'Aire Marine Protégée de la Côte Agathoise, Colloque CARtographie des HAbitats Marins Benthiques : de l'Acquisition à la Restitution CARHAMB'AR, Brest, 14 - 16 mars 2017, pp 37-40. http://www.carhambar.org 